\title{
Gut Microbiota: Physiology and Relationship with Inflammatory Bowel Disease
}

\author{
Chun-Yu Lin", Yeong-Jang Lin, Hung-An Chen \\ Division of Allergy-Immunology-Rheumatology, Department of Internal Medicine, Chi Mei Medical Center, Tainan, Taiwan \\ Email: *linchunyumed@gmail.com
}

Received September 3, 2013; revised October 1, 2013; accepted October 9, 2013

Copyright (C) 2013 Chun-Yu Lin et al. This is an open access article distributed under the Creative Commons Attribution License, which permits unrestricted use, distribution, and reproduction in any medium, provided the original work is properly cited.

\begin{abstract}
The intestinal microbiota, which evolved over tens of thousands of years along with their human hosts, constitutes a complex and diverse ecosystem whose composition differs from person to person. Accumulating evidence indicates that commensal bacteria exert numerous beneficial physiological effects for humans, including nutrition, protection, metabolism, organ development and immunomodulation. However, mucosal immune responses to intestinal microflora require precise control to allow appropriate defense against potential pathogens but restrict the immune response to beneficial resident bacteria. The task of intestinal homeostasis is accomplished by epithelium and specialized immune system in the gastrointestinal tract. Alternation in the composition of the bacterial community, consisting of increased representation of harmful species or under presence of protective species, or dysbiosis has been linked to various chronic and inflammatory disorders, such as inflammatory bowel disease. An improved understanding of the underlying molecular mechanisms of host-microorganism interactions could bring new insights into onset and pathogenesis of several autoimmune diseases. This review will discuss physiologic properties of commensal microbiota and how dysregulated immune responses to them contribute to chronic mucosal inflammation.
\end{abstract}

Keywords: Commensal Microbiota; Inflammatory Bowel Disease; Dysbiosis; Homeostasis

\section{Introduction}

No life exists in absolute isolation, and all multicellular organisms live in close proximity and interact with neighboring microorganisms, either in mutualistic or commensal relationships. The human body harbors a large number of microbes, consisting of bacteria, fungi, viruses and some kinds of unicellular eukaryotes, among which bacteria were most intensively studied over the past few years. The microbiota, also termed microflora or normoflora, represents the collection of microbes that live in peaceful coexistence with their hosts [1]. It is estimated that the human microflora carries about $10^{14}$ bacterial cells, a number ten times greater than the total number of human cells within the body [2]. Although virtually every body surface exposed to the external environment becomes colonized by various microbes soon after birth, the gastrointestinal tract has the largest surface area and by far the most heavily colonized region. The bacteria residing in the mammalian intestine were traditionally regarded just as organisms living together

\footnotetext{
*Corresponding author.
}

with the host but without much interaction. Thus, their existence in the gut did not draw much attention from researchers in the field of immunology and gastroenterology for a long period of time. Nowadays, there is growing evidence indicating that commensal microbiota are involved in a variety of important physiological function in the gut and play a critical role in the maintenance of human health. An imbalance between gut microflora with unfavorable or harmful effects and those with beneficial or advisable reaction, termed dysbiosis, may result in unresolving chronic inflammation and autoimmune disease, such as inflammatory bowel disease. In this review, we introduce various physiologic functions of intestinal microflora and mechanisms of intestinal homeostasis, recent progress that had been made in host-microbiota relationships and how these mechanisms failed to chronic bowel inflammation.

\section{Characteristics and Localization of the Commensal Microbiota}

The intestinal tract of fetus is sterile, and a wide variety 
of environmental microorganisms start to colonize upon passage through the birth canal [3]. Patterns of initial colonization have a strong impact on future texture and function of adult microflora [4]. The intestinal microbeota along its whole length is not homogenous and differs substantially in both density and composition in different gut segments. The number of microbes in stomach is low mainly owing to its acidity and the concentration gradually increases along the proximal to distal compartment of the intestinal tract, where distal ileum and colon are represented by most densely populated organs [5]. In addition to discrepancy at longitudinal levels, there is also difference of normal flora composition at altitudinal levels. Lower ratio of anaerobes to aerobes is observed at the mucosal surface than in the luminal area. Although over 50 bacterial phyla have been identified in the natural world, only two phyla dominate in the human gut flora: the Bacteroidetes and the Firmicutes [6]. Firmicutes is mainly composed of Gram-positive bacteria and is by far the phylum of greatest diversity in the human gastrointestinal tract with low GC content. Bacterial species belonging to Firmicutes include Lactobacillus and Clostridium [7]. Relatively few phyla in the human gut tract are represented by Proteobacteria, which contain many well-known pathogens, such as Escherichia coli and Actinobacteria. Bifidobacteria, commonly found in the colon, are considered to be the most representative genus for the Actinobacteria phylum [8]. It had been suggested that the number of species inhabiting the human gut are more than 500, based on traditional culturing methods [9]. Nevertheless, giving the fact that the majority of bacteria in the intestine are obligatory anaerobic and not all cultivable, the number is apparently underestimated. With the expanded knowledge of molecular biology and culture-independent techniques, it has been showed that over 36,000 species of bacteria reside in the human gut by using rRNA sequence analysis in a recent study [10].

\section{Determining Factors of the Intestinal Flora}

The microbial makeup of the mammalian gastrointestinal tract differs from person to person and several lines of evidence have suggested that the host genetics have a strong impact. A study comparing the composition of intestinal microflora between adult female monozygotic, dizygotic twin pairs and their mothers revealed similarity among family members [11]. Moreover, reduced abundance of Bacteroidetes and a comparable increase in Firmicutes was observed in genetically obese mice in comparison with their genetically lean siblings [12]. Little is known about how certain DNA variations can result in the assembling and perpetuation of specific microbiota profiles. It is likely that modulation of bacterial population is through metabolic process.
Bacteria from the maternal vagina and gut also have a great influence on the composition of microflora, since they represent a major source of colonization within hours after birth, especially in vaginally born infants [13]. Infants delivered vaginally had $E$. coli and Streptococcus in their stools as the main species during the first few days of birth [14], which were replaced by Bacteroidetes and Bifidobacterium and Clostridium species one to two weeks later [15]. In contrast, babies born by means of cesarean section have reduced number of Bacteroidetes and Bifidobacteria associated with a greater abundance of $C$. difficile colonization [16], and their profiles of microbiota more closely resemble the mother's skin. In addition, Enterobacter and Klebsiella species populate the gut more rapidly in these infants. Interestingly, children born through caesarean section are at greater risk of allergic disease and the reason for this was proposed to be associated with altered composition of microbiota as there is evidence showing decreased diversity of gut microbiota during first two years of life of these children [17].

The feeding regimen and nutrition play a vital role in determining the pattern of microbial colonization. Breast milk is of paramount importance in modulating bacterial population of infant's intestinal tract, as it not just serves as energy sources but contains a variety of oligosaccharide and bioactive substances, which are believed to promote growth of certain species of microbiome [18]. Besides enriched in essential fatty acids, breast milk also contains high levels of transforming growth factor (TGF)- $\beta 1$ and secretory immunoglobulin A (IgA). These factors fully transferred to infant's gut by breast-feeding have a major role in shaping the regulatory immune network [19]. However, the maternal $\lg$ A repertoire is also influenced by her experience of microbial exposure. The numbers of Bifidobacteria in breastfed babies were shown to be twice than those in formula-fed infants [20]. It was also revealed that $E$. coli, Bacteroidetes and $C$. Difficile were detected far less in breastfed infants. But there is inconsistency in some studies [21]. The reason may be due to different race or sampling method, and individual-specific milk content.

Other factors influencing the composition of bacterial communities include diet, antibiotics use and stress. Although the microbiota undergoes substantial changes from birth to children, it is surprising that the adult microbiota is relatively stable. A recent study using the method of low-error amplicon sequencing to analyze fecal material from 37 health adults has demonstrated that $60 \%$ of strains of an individual's microbial communities remain over the course of 5 years [22]. Thus, it appeals that environmental changes and perturbations, such as antibiotics use, only lead to transient microbiota destabilization [23]. The mechanism of the phenomenon 
remains to be elucidated.

\section{Beneficial Effects of Gut Microbiota}

Commensal microbiota of human confer a health benefit to the host through exerting a range of important functions about metabolism, nutrition, protection, digestion and immunity (Table 1). The existence of microflora protects the host from enteric pathogen invasion through local mechanisms, such as competition for adhesion sites and essential nutrients, production of antimicrobial substances. The ability to bind to eukaryotic cell membrane receptor is an important determinant of bacterial virulence. It has been shown that the physical existence of certain strain of bacteria is in the ileum preclude Salmonella enteritidis and prevents fatal infection [24]. Resistance to pathogen is also attributed to acid environment established by Lactobacillus which produce lactic acid. Not only epithelial cell of gut produce antimicrobial peptides, which will be described later, commensal microbiomes also synthesis antimicrobial material to inhibit expansion of other community, called bacteriocin. Bacteriocins have a narrow spectrum of antimicrobial activity and are activated after released into the external environment [25].

Table 1. Physiologic functions of commensal microbiota.

Structural functions
Epithelial barrier fortification
Stabilization of tight junctions
Epithelial cell proliferation and differentiation
Protective functions
Competition for nutrients
Competition for attachment site
Pathogen displacement
Production of antimicrobial factors (bacteriocins)
Metabolic functions
Essential vitamins synthesis (vitamin K and B12)
Fermentation of non-digestible carbohydrates
Production of short chain fatty acids
Imoluagion of energy
Induction of IgA synthesis
Immune functions

Short chain fatty acids, including butyrate, succinate and propionate, which were formed by degradation of indigestible dietary substances by luminal bacteria, serve as the energy resource of colonic epithelium. Butyrate was also shown to have a role in mediating differentiation and cell cycle of colonocytes, immunomodulation, maintenance of epithelial barrier integrity and inhibition of inflammation and carcinogenesis [26,27]. In addition, certain vitamins, especially vitamin $\mathrm{B}$ complex and $\mathrm{K}$, which are generated by propionic acid bacteria, are crucial for human survival [28].

Morphology of intestine and epithelial cell turnover rates was greatly influenced by bacteria. Intestinal abnormalities of the germ-free animals consist of longer villi, shorter crypts, impairment in the peristaltic activity [29], and lower brush border enzyme activities in comparison to those raised conventionally [30,31]. The aberrant morphology and function can be corrected by oral inoculation of commensal flora or nonpathogenic $E$. coli [31,32]. Thus, microbiota is critically involved in apoptosis, proliferation and differentiation of epithelium.

Maintenance of intestinal epithelium barrier integrity is important as it prevents noxious agents and unwanted microorganism getting into systemic circulation and inducing harmful inflammation. It is surprising that various microbiota members participate in enhancing barrier function of epithelium. Administration of lactobacillus prevents gut leakiness and spontaneous colitis development in interleukin 10 gene-deficient mice [33]. Increase permeability and leukocyte infiltration of colon in dextran sodium sulfate (DSS) treated mice were ameliorated greatly by concomitant administration of probiotic Escherichia coli Nissle 1917 [34]. Moreover, mucosa injury by stress or pathogen assault was shown to be reversed in the presence of probiotics [35]. The fortification of epithelial barrier function appeals to depend on Toll-like receptor engagement [36].

A novel function of microbiota was discovered recently. In the past few years, there was increasing evidence supporting that indigenous gut microbes is closely associated with nervous system development and maturation. Data accumulated from animal studies indicate that disturbance of the microbiota can change behavior, and germ-free mice exhibit an exaggerated stress responses and anxiety-like behavior compared with specific pathogen-free mice [37]. Other nervous system abhypothalamic-pituitary-adrenal axis and decreased perception of inflammatory pain [38]. In human study, Clostridial species were found to be more prevalent in a small number of autistic patients but cause-effect relationship remains speculative [39]. Therefore, with the emerging concept of gut-brain axis, modulation of gut bacteria may be a promising target to treat complex psynormalities in germ-free mice include perturbation of 
chiatric disease.

\section{Control of Indigenous Microorganisms}

Microbiota has a number of beneficial contribution to health, but the host has to keep commensal and pathogenic bacteria under control as overgrowth of the bacterial communities results in mucosa damage, even systemic inflammation if spread to other sites in the body which should be sterile. A variety of mechanisms are developed to prevent microbiome dissemination, including physical barrier formed by mucus layer and epithelium continuity, anti-microbial peptide and secretory IgA.

\subsection{Mucus}

The inner surface of gut from stomach to colon is coated by a thick mucus layer, which are produced by goblet cell that lie in the epithelium of the gastrointestinal tract. The mucus can be divided into outer layer and inner layer. The outer layer, composed of complex mucin glycoprotein, is easily removed by brushing, whereas the inner layer, actually representing the glycocalyx of intestinal epithelial cell, is composed of membrane-bound glycoprotein and firmly adherent to the epithelial cells. [40] Microbes are associated mostly in the outer layer but not present in the inner glycocalyx, as shown by recent studies using 16S rRNA fluorescence in situ hybridization (FISH) [41]. Mice with mucin MUC1 deficiency were shown to have uncontrolled dissemination of Campylobacter jejuni following oral infection [42]. Thus, mucus layer represents an efficient barrier to prevent violation and direct contact between concentrated bacteria in the intestine and the epithelium, then avoid immune system overactivation. The importance of mucus layer in epithelial protection was illustrated by the fact that mice with defective mucin production developed colitis spontaneously [43].

\subsection{Epithelium and Tight Junction}

The intestine is exposed to an unlimited number and variety of antigens, derived from ingested food or microbiomes. The bowel must allow efficient absorption of ions and nutrients but block entry of potentially harmful luminal microorganisms. The task is accomplished by epithelial barrier, a monocellular layer that acts as a critical interface between the outside lumen and host tissues. Luminal bacteria get access to circulation by two routes: transcellular and paracellular. Even luminal substances are endocytosed into epithelial cells, transcellular transport are limited by enzymatic degradation within enterocyte, so its way to submucoal compartment was prevented. However, bacterial translocation across epithelium via the transcellular pathway was found to be increased in the status of inflammation or stress as a re- sult of energy crisis (presence of tumor necrosis factor-a or hypoxia) $[44,45]$. Invasion of bacteria or noxious antigen through paracellular pathway was restricted by tight function forming the intercellular barrier between epithelial cells. Four different types of transmembranous junctional protein were identified within tight junction, occludin, junctional adhesion molecule, claudins and tricellulin [46]. In the conditions associated with increased mucosa permeability, such as celiac disease or inflammatory bowel disease, defective tight junction structure as downregulation of occluding, claudin 4, claudin 5 and claudin 8 was clearly demonstrated [47, 48].

\subsection{IgA}

$\operatorname{IgA}$ is the second most common immunoglobulin in human serum (after IgG) and is the predominant immunoglobulin found in mucosal secretions. IgA can exist in a dimeric form called secretory IgA (sIgA). The structure of sIgA protects the immunoglobulin from being degraded by proteolytic enzymes, thus sIgA can survive in the luminal space of gastrointestinal tract and provide the host protection by binding bacteria and neutralizing toxins. Recent evidence demonstrates that $\operatorname{sIg} \mathrm{A}$ is not only associated with blockage of infection but also involved in control of bacterial load and composition in the intestine. In a recent mouse study, IgA have been shown to reduce the colonization of segmented filamentous bacteria in the ileum, a member of the indigenous gut mucosal microbiota [49]. One group revealed that the majority of human colon microbiota were coated with specific IgA [50]. Moreover, recent studies also find more vigorous immune response and metabolic derangement in mice with $\operatorname{Ig} \mathrm{A}$ deficiency [51,52], supporting the role of $\operatorname{IgA}$ in diminishing the immune reaction to the commensals.

\subsection{Antimicrobial Peptides}

Antimicrobial peptides (AMPs), an evolutionarily conserved component of innate immunity, are a diverse group of molecules with broad spectrum of antimicrobial activity against bacteria, viruses, and fungi. Cathelicidins and defensins are major groups of AMPs and other minor representations include C-type lectins, lysozyme $\mathrm{C}$, and secretory phospholipase A2 type IIA [53]. Although enterocytes secrete some AMPs, but major producer in the gut are Paneth cells located at the base of small intestine crypts. It is becoming increasingly evident that AMPs play a major role in shaping the repertoire of the commensal microbiota. Cryptdins are mouse AMPs whose structure and function are similar to human $\alpha$-defensins. It was demonstrated that mice with defective cryptdins production were more susceptible to Salmonella infection than wild-type counterparts [54]. Moreover, a recent 
study revealed that mice with genetic deficiency of matrix-metalloproteinase-7, which was required to convert precursors of cryptdin into their active form, had altered ratio of Firmicutes to Bacteroidetes phyla [55]. These findings support critical role of AMPs in the intestinal homeostasis.

\section{Inflammatory Bowel Disease}

Inflammatory bowel disease (IBD), consisting of two different diseases, Crohn's disease (CD) and ulcerative colitis (UC), is a chronic inflammatory disease of gastrointestinal tract characterized by episodes of relapse and remission. It has long been known that the commensal microbiota and pathogenic bacteria are closely associated with the development and progression of IBD. There are several lines of evidence supporting the role of microorganisms in IBD, including the bacterial load are highest in the terminal ileum and colon, as described above, which are also sites most frequently involved in IBD. In addition, spontaneous colitis failed to develop in IL-2 or IL-10-deficient mice reared in germ-free environment and antibiotics administration was capable of ameliorating the degree of bowel inflammation in both human patients and animal models. Understanding interaction between the commensals, mucosa epithelium and immune system and failure of regulatory mechanisms help to develop therapeutic strategies to restore the balance.

\subsection{Altered Microbiota Composition in IBD Hosts}

Marked decrease in the diversity of gut microbiota was observed in patients with IBD compared to healthy individuals. The exact reason was not well-known and a diminished portion of certain beneficial bacterial species may contribute to the phenomenon. Reduced abundance of Faecalibacterium prausnitzii, Lactobacillus coleohominis, Bacteroides sp and Streptococcus gallolyticus have been reported in the bowel of IBD patients using molecular methods [56]. However, some groups, especially pathogenic Escherichia coli and Shigella flexneri, were shown to have increased representation in individuals suffering from CD [56]. Faecalibacterium prausnitzii, a member of Firmicutes phylum, is a common anaerobic bacteria colonized in the human gut that has been widely accepted as beneficial for the intestine health and its immunoregulatory properties were confirmed in various studies. In vitro stimulation of human peripheral blood mononuclear cells with $F$. prausnitzii increases their generation of IL-10 and TGF- $\beta 1$. In addition, $F$. prausnitzii are capable of inducing the Foxp3 and regulatory $\mathrm{T}$ cell production and ameliorating the gut inflammation in trinitrobenzene sulfonic acid (TNBS)-induced colitis rat models [57]. A human study analyzing resected gut from patients suffering from CD revealed that patients with depletion of $F$. prausnitzii were more likely to have disease recurrence within six months after surgery [58]. Thus, changes in the constitution of gut microflora, especially reduced number of protective bacteria, are highly correlated with development and perpetuation of IBD.

\subsection{Altered Gut Mucus Barrier}

The mucus layer of IBD patients is often thinner and more discontinuous compared with normal individuals, leaving large areas of bare epithelium [59]. The reduction of mucus thickness is largely attributed to the decreased number of goblets cells in both human and animal studies [59,60]. Diminished production of mucin protein MUC 1, MUC2, MUC4, MUC5B, MUC12, MUC13, MUC17, MUC20 has been demonstrated in both CD and UC patients. MUC2 polymorphism was linked to $\mathrm{CD}$, whereas MUC4 and MUC13 polymorphism were linked to UC [61]. Mice with MUC2 deficiency were reported to have markedly deficient mucus layers accompanied by altered mucosa morphology, increased gut permeability, increased inflammatory cell infiltration and increased susceptibility to DSS-induced colitis [62]. Moreover, missense mutation in Muc2 in mice resulted in aberrant mucin synthesis, impaired mucin production, diminished mucus layer and spontaneous inflammation in the gut. These mice also had abnormal goblet cell morphology on histological examination, which was analogous to changes in the patients with UC [62]. There is evidence showing that microbiota and its products can modulate mucin production and secretion. Reduced thickness and altered structure of mucus layer has been observed in the colon of germ-free rats [63]. Consistently, oral administration of Lactobacillus to rats lead to significantly increased MUC2 gene expression and mucin production [64]. Taking together, these findings suggest a role for the commensal microbiota in the formation and maintenance of the mucus barrier, and importance of the aberrant mucin synthesis in the pathogenesis of IBD.

\subsection{Aberrant Recognition of Bacteria in IBD}

The dysregulation of innate intestinal immune responses against bacterial microbiota is believed to be highly involved in the onset and perpetuation of IBD. Intestinal epithelial cells constitutively express a range of pattern recognition receptors (PRRs), such as Toll-like receptors (TLRs) and nucleotide-binding oligomerization domain -like receptors (NLR) families, allowing them to sense the presence of the bacteria or its metabolites and initiate appropriate innate immune responses, usually by activating proinflammatory cytokine genes. One of mechanism of tolerance to enormous masses of intestinal bacte- 
ria was shown as spatial restriction of TLR. The fact that TLR expression limited to the basolateral surface of enterocytes located in the crypts [65] ensures that an immune response is only elicited when microorganisms intrude the host epithelial layer. A recent study investigating the surface expression of TLR in biopsy samples from patients with IBD compared with healthy individuals revealed upregulation of TLR-2 and TLR-4 in the terminal ileum, outside of the crypts, of patients with inactive and active $\mathrm{UC}$ [66]. On the other hand, intestinal macrophages typically do not express innate-immune receptor CD14 and are not capable of producing a large amount of proinflammatory cytokines against commensal microflora, which appeals to be a tolegenic mechanism within mucosa immune system. It has been shown that patients with $C D$ had significantly higher number of these CD14+ macrophages compared with normal control subjects [67]. These findings suggest that augmented and improper immune responses to the commensal microbiota play a crucial role in IBD. Based on the theory, it is expected that aborted TLR signaling or its downstream adaptor molecule MyD88 pathway might attenuate intestinal inflammation. However, mice with genetic deficiency in TLR-4 or MyD88 exhibit increased severity of colitis and higher mortality rate accompanied with more apoptosis of epithelium and defective epithelial restitution in DSS-induced colitis model $[68,69]$. The findings in these mice models were comparable to those with starvation of commensal bacteria in DSS models [68], illustrating the crucial role of existence of commensal microbiota and TLR signaling in the maintenance of epithelium integrity. Thus, constitutive tonic sensing of microorganisms by pattern recognition receptors in epithelial cells maintains intestinal homeostasis. Over- or understimulation of innate immune system results in uncontrolled mucosa inflammation.

The protective function of pattern recognition receptors are not limited to TLR as nucleotide binding and oligomerization domain-containing protein 2 (NOD2) was shown to exert similar effect in recent study. NOD2 is a cytoplasmic receptor involved in sensing bacteria cell wall components and regulating inflammatory processes. Association of single nucleotide Polymorphism or mutation of NOD2 with CD has been long known but how NOD2 increases susceptibility to CD remains unclear [70]. One hypothesis stated that the defect in the innate immunity due to NOD2 mutation allows intracellular bacteria to escape the first-line defense thereby leading to unrestricted gut bacterial growth and an enhanced adaptive immune response. There is supporting evidence for this theory that mice with NOD2 deficiency were shown to display altered microbiota composition and higher bacterial load in the terminal ileum and feces compared with wild-type counter parts [71]. Furthermore, a reduction in the production of alpha-defensins by $\mathrm{Pa}-$ neth cells related to NOD2 mutation was observed in patients with $\mathrm{CD}$ [72]. Other groups have realized that NOD2 deficient mice failed to downregulate TLR-2 signaling on antigens challenge and subsequent colitis developed [73]. Moreover, a recent study demonstrated that engagement of muramyl dipeptide (MDP), a NOD2 ligand, to its receptor downregulates TLR-3, TLR-4, TLR-5, TLR-9 responses as well as TLR-2 responses and protects mice from chemical-induced colitis [74].

Although a large number of studies have shown that perturbation of bacterial communities and intestinal barrier dysfunction occur in IBD, there is controversy about whether dysbiosis is the starting point or just the consequence of inflammation. An interesting finding is that the richness of bacterial communities differs between noninflamed mucosa and fully inflamed tissue in IBD samples, with a decline of diversity from the former to the latter [75]. Therefore, it is also possible that inflammation precede the onset of dysbiosis and is the cause of the local decline in bacteria burden and diversity.

\section{Conclusion}

Inflammatory bowel disease, a multi-factorial disease, arises from complex interactions of environment factors, intestinal epithelium, immune system and genetic makeup of the host. The commensal microbiota are key players in the maintenance of intestinal homeostasis among various environmental factors. It is increasingly apparent that influence of the microbiota on intestine environment is bi-directional, both proinflammatory and regulatory. Balance between proinflammatory and anti-inflammatory signals is crucial in the prevention of pathogen infection and inflammation-mediated injury. In the past few years, tremendous progress has been made in our knowledge of interaction between gut microflora and immune system with the advance of modern molecular methods. Manipulation of the gut micorbiota to enhance the beneficial components represents a promising therapeutic measure in the treatment of various diseases. However, provided the fact of unsatisfactory response of current treatment modality in inflammatory bowel disease, the field is still in its infancy. A better understanding of microbiota and immune system interaction will lead to the development of new therapies to successfully relieve idiopathic inflammatory bowel disease in humans.

\section{REFERENCES}

[1] C. Kunz, S. Kuntz and S. Rudloff, "Intestinal Flora," Advances in Experimental Medicine and Biology, Vol. 639, 2009, pp. 67-69. http://dx.doi.org/10.1007/978-1-4020-8749-3_6

[2] R. E. Ley, D. A. Peterson and J. I. Gordon, "Ecological 
and Evolutionary Forces Shaping Microbial Diversity in the Human Intestine," Cell, Vol. 124, No. 4, 2006, pp. 837-848. http://dx.doi.org/10.1016/j.cell.2006.02.017

[3] T. Sobko, M. Norman, E. Norin, L. E. Gustafsson and J. O. Lundberg, "Birth-Related Increase in Intracolonic Hydrogen Gas and Nitric Oxide as Indicator of Host-Microbial Interactions," Allergy, Vol. 60, No. 3, 2005, pp. 396-400.

http://dx.doi.org/10.1111/j.1398-9995.2005.00737.x

[4] V. Buccigrossi, E. Nicastro and A. Guarino, "Functions of Intestinal Microflora in Children," Current Opinion in Gastroenterology, Vol. 29, No. 1, 2013, pp. 31-38. http://dx.doi.org/10.1097/MOG.0b013e32835a3500

[5] W. E. C. Moore and L. V. Holdeman, "Human Fecal Flora: The Normal Flora of 20 Japanese-Hawaiians," Applied Microbiology, Vol. 27, No. 5, 1974, pp. 961-979.

[6] P. B. Eckburg, E. M. Bik, C. N. Bernstein, et al., "Diversity of the Human Intestinal Microbial Flora," Science, Vol. 308, No. 5728, 2005, pp. 1635-1638.

http://dx.doi.org/10.1126/science.1110591

[7] S. Cusack, M. J. Claesson and P. W. O'Toole, "How Beneficial Is the Use of Probiotic Supplements for the Aging Gut?" Aging Health, Vol. 7, No. 2, 2011, pp. 179186. http://dx.doi.org/10.2217/ahe.11.8

[8] M. Kleerebezem and E. E. Vaughan, "Probiotic and Gut Lactobacilli and Bifidobacteria: Molecular Approaches to Study Diversity and Activity," Annual Review of Microbiology, Vol. 63, 2009, pp. 269-290. http://dx.doi.org/10.1146/annurev.micro.091208.073341

[9] J. Xu J and J. I. Gordon, "Honor thy Symbionts," Proceedings of the National Academy of Sciences of the United States of America, Vol. 100, No. 18, 2003, pp. 10452-10459. http://dx.doi.org/10.1073/pnas.1734063100

[10] D. N. Frank, A. L. St. Amand, R. A. Feldman, E. C. Boedeker, N. Harpaz and N. R. Pace, "Molecular-Phylogenetic Characterization of Microbial Community Imbalances in Human Inflammatory Bowel Diseases," Proceedings of the National Academy of Sciences of the United States of America, Vol. 104, No. 34, 2007, pp. 13780-13785. http://dx.doi.org/10.1073/pnas.0706625104

[11] P. J. Turnbaugh, M. Hamady, T. Yatsunenko, et al., "A Core Gut Microbiome in Obese and Lean Twins," Nature, Vol. 457, No. 7228, 2009, pp. 480-484. http://dx.doi.org/10.1038/nature07540

[12] R. E. Ley, F. Bäckhed, P. Turnbaugh, C. A. Lozupone, R. D. Knight and J. I. Gordon, "Obesity Alters Gut Microbial Ecology," Proceedings of the National Academy of Sciences of the United States of America, Vol. 102, No. 31, 2005, pp. 11070-11075. http://dx.doi.org/10.1073/pnas.0504978102

[13] C. Palmer, E. M. Bik, D. B. DiGiulio, D. A. Relman and P. O. Brown, "Development of the Human Infant Intestinal Microbiota," PLoS Biology, Vol. 5, No. 7, 2007, pp. 1556-1573.

http://dx.doi.org/10.1371/journal.pbio.0050177

[14] R. A. Caicedo, R. J. Schanler, N. Li and J. Neu, "The Developing Intestinal Ecosystem: Implications for the Neonate," Pediatric Research, Vol. 58, No. 4, 2005, pp. 625-628.
http://dx.doi.org/10.1203/01.PDR.0000180533.09295.84

[15] R. Ortega, A. Loria and R. Kelly, "A Semiglobally Stable P. L. Stark PL and A. Lee, "The Microbial Ecology of the Large Bowel of Breast-Fed and Formula-fed Infants during the First Year of Life," Journal of Medical Microbiology, Vol. 15, No. 2, 1982, pp. 189-203.

http://dx.doi.org/10.1099/00222615-15-2-189

[16] J. Penders, C. Thijs, C. Vink, et al., "Factors Influencing the Composition of the Intestinal Microbiota in Early Infancy," Pediatrics, Vol. 118, No. 2, 2006, pp. 511-521. http://dx.doi.org/10.1542/peds.2005-2824

[17] H. Garn, J. F. Neves, R. S. Blumberg and H. Renz, "Effect of Barrier Microbes on Organ-based Inflammation," The Journal of Allergy and Clinical Immunology, Vol. 131, No. 6, 2013, pp. 1465-1478. http://dx.doi.org/10.1016/j.jaci.2013.04.031

[18] R. Jenness, "The Composition of Human Milk," Seminars in Perinatology, Vol. 3, No. 3, 1979, pp. 225-239.

[19] C. Lindner, B. Wahl, L. Föhse, et al., "Age, Microbiota and T Cells Shape Diverse Individual IgA Repertoires in the Intestine," The Journal of Experimental Medicine, Vol. 209, No. 2, 2012, pp. 365-377. http://dx.doi.org/10.1084/jem.20111980

[20] E. Bezirtzoglou, A. Tsiotsias and G. W. Welling, "Microbiota Profile in Feces of Breast- and Formula-Fed Newborns by Using Fluorescence in Situ Hybridization (FISH)," Anaerobe, Vol. 17, No. 6, 2011, pp. 478-482. http://dx.doi.org/10.1016/j.anaerobe.2011.03.009

[21] I. Adlerberth and A. E. Wold, "Establishment of the Gut Microbiota in Western Infants," Acta Paediatrica, Vol. 98, No. 2, 2009, pp. 229-238. http://dx.doi.org/10.1111/j.1651-2227.2008.01060.x

[22] J. J. Faith, J. L. Guruge, M. Charbonneau, et al., "The Long-term Stability of the Human Gut Microbiota," Science, Vol. 341, No. 6141, 2013, in Press. http://dx.doi.org/10.1126/science.1237439

[23] J. Jalanka-Tuovinen, A. Salonen, J. Nikkilä, et al., "Intestinal Microbiota in Healthy Adults: Temporal Analysis Reveals Individual and Common Core and Relation to Intestinal Symptoms," PLoS One, Vol. 6, No. 7, 2011, Article ID: e23035. http://dx.doi.org/10.1371/journal.pone.0023035

[24] C. D. Garland, A. Lee and M. R. Dickson, "Segmented Filamentous Bacteria in the Rodent Small Intestine: Their Colonization of Growing Animals and Possible Role in Host Resistance to Salmonella," Microbial Ecology, Vol. 8, No. 2, 1982, pp. 181-190. http://dx.doi.org/10.1007/BF02010451

[25] T. Baba and O. Schneewind, "Instruments of Microbial Warfare: Bacteriocin Synthesis, Toxicity and Immunity," Trends in Microbiology, Vol. 6, No. 2, 1998, pp. 66-71. http://dx.doi.org/10.1016/S0966-842X(97)01196-7

[26] M. Comalada, E. Bailón, O. de Haro, et al., "The Effects of Short-Chain Fatty Acids on Colon Epithelial Proliferation Andsurvival Depend on the Cellular Phenotype," Journal of Cancer Research and Clinical Oncology, Vol. 132, No. 8, 2006, pp. 487-497. http://dx.doi.org/10.1007/s00432-006-0092-x

[27] A. J. Leonel and J. I. Alvarez-Leite, "Butyrate: Implica- 
tions for Intestinal Function," Current Opinion in Clinical Nutrition and Metabolic Care, Vol. 15, No. 5, 2012, pp. 474-479.

http://dx.doi.org/10.1097/MCO.0b013e32835665fa

[28] A. Thierry, S. M. Deutsch, H. Falentin, M. Dalmasso, F. J. Cousin and G. Jan, "New Insights into Physiology and Metabolism of Propionibacterium freudenreichii," International Journal of Food Microbiology, Vol. 149, No. 1, 2011, pp. 19-27.

http://dx.doi.org/10.1016/j.ijfoodmicro.2011.04.026

[29] E. Husebye, P. M. Hellström and T. Midtvedt, "Intestinal Microflora Stimulates Myoelectric Activity of Rat Small Intestine by Promoting Cyclic Initiation and Aboral Propagation of Migrating Myoelectric Complex," Digestive Diseases and Sciences, Vol. 39, No. 5, 1994, pp. 946956. http://dx.doi.org/10.1007/BF02087542

[30] B. P. Willing and A. G. Van Kessel, "Enterocyte Proliferation and Apoptosis in the Caudal Small Intestine is Influenced by the Composition of Colonizing Commensal Bacteria in the Neonatal Gnotobiotic Pig," Journal of Animal Science, Vol. 85, No. 12, 2007, pp. 3256-3266. http://dx.doi.org/10.2527/jas.2007-0320

[31] H. Kozakova, J. Kolinska and Z. Lojda, "Effect of Bacterial Monoassociation on Brush-border Enzyme Activities in Ex-Germ-Free Piglets: Comparison of Commensal and Pathogenic Escherichia coli Strains" Microbes and Infection/Institute Pasteur, Vol. 8, No. 11, 2006, pp. 26292639.

[32] T. W. Shirkey, R. H. Siggers, B. G. Goldade, et al., "Effects of Commensal Bacteria on Intestinal Morphology and Expression of Proinflammatory Cytokines in the Gnotobiotic Pig," Experimental Biology and Medicine (Maywood, N.J.), Vol. 231, No. 8, 2006, pp. 1333-1345.

[33] K. L. Madsen, J. S. Doyle, L. D. Jewell, M. M. Tavernini and R. N. Fedorak, "Lactobacillus Species Prevents Colitis in Interleukin 10 Gene-Deficient Mice," Gastroenterology, Vol. 116, No. 5, 1999, pp. 1107-1114. http://dx.doi.org/10.1016/S0016-5085(99)70013-2

[34] S. N. Ukena, A. Singh, U. Dringenberg, et al., " Probiotic Escherichia coli Nissle 1917 inhibits leaky Gut by Enhancing Mucosal Integrity," PLoS One, Vol. 2, No. 12, 2007, Article ID: e1308. http://dx.doi.org/10.1371/journal.pone.0001308

[35] F. Lutgendorff, L. M. Akkermans and J. D. Söderholm, "The Role of Microbiota and Probiotics in Stress-Induced Gastro-Intestinal Damage," Current Molecular Medicine, Vol. 8, No. 4, 2008, pp. 282-298. http://dx.doi.org/10.2174/156652408784533779

[36] E. Cario, G. Gerken and D. K. Podolsky, "Toll-Like Receptor 2 Controls Mucosal Inflammation by Regulating Epithelial Barrier Function," Gastroenterology, Vol. 132, No. 4, 2007, pp. 1359-1374.

http://dx.doi.org/10.1053/j.gastro.2007.02.056

[37] S. M. Collins and P. Bercik, "The Relationship between Intestinal Microbiota and the Central Nervous System in Normal Gastrointestinal Function and Disease," Gastroenterology, Vol. 136, No. 6, 2009, pp. 2003-2014. http://dx.doi.org/10.1053/j.gastro.2009.01.075

[38] J. F. Cryan and T. G. Dinan, "Mind-Altering Microor- ganisms: The Impact of the Gut Microbiota on Brain and Behaviour," Nature Reviews. Neuroscience, Vol. 13, No. 10, 2012, pp. 701-712.

[39] Y. Song, C. X. Liu and S. M. Finegold, "Real-Time PCR Quantitation of Clostridia in Feces of Autistic Children," Applied and Environmental Microbiology, Vol. 70, No. 11, 2004, pp. 6459-6465. http://dx.doi.org/10.1128/AEM.70.11.6459-6465.2004

[40] C. Atuma, V. Strugala, A. Allen and L. Holm, "The Adherent Gastrointestinal Mucus Gel Layer: Thickness and Physical state in Vivo," American Journal of Physiology. Gastrointestinal and Liver Physiology, Vol. 280, No. 5, 2001, pp. 922-929.

[41] M. E. Johansson, M. Phillipson, J. Petersson, A. Velcich, L. Holm and G. C. Hansson, "The Inner of the Two Muc2 Mucin-Dependent Mucus Layers in Colon is Devoid of Bacteria," Proceedings of the National Academy of Sciences of the United States of America, Vol. 105, No. 39, 2008, pp. 15064-15069. http://dx.doi.org/10.1073/pnas.0803124105

[42] J. L. McAuley, S. K. Linden, C. W. Png, R. M. King, H. L. Pennington, S. J. Gendler, T. H. Florin, G. R. Hill, V. Korolik and M. A. McGuckin, "MUC1 Cell Surface Mucin Is a Critical Element of the Mucosal Barrier to Infection," The Journal of Clinical Investigation, Vol. 117, No. 8, 2007, pp. 2313-2324. http://dx.doi.org/10.1172/JCI26705

[43] H. Kawashima, "Roles of the Gel-Forming $\mathrm{MUC}_{2}$ Mucin and Its O-Glycosylation in the Protection against Colitis and Colorectal Cancer," Biological and Pharmaceutical Bulletin, Vol. 35, No. 10, 2012, pp. 1637-1641. http://dx.doi.org/10.1248/bpb.b12-00412

[44] E. C. Clark, S. D. Patel, P. R. Chadwick, G. Warhurst, A. Curry and G. L. Carlson, "Glutamine Deprivation Facilitates Tumour Necrosis Factor Induced Bacterial Translocation in Caco-2 Cells by Depletion of Enterocyte Fuel Substrate," Gut, Vol. 52, No. 2, 2003, pp. 224-230. http://dx.doi.org/10.1136/gut.52.2.224

[45] C. L. Wells, E. M. VandeWesterlo, R. P. Jechorek and S. L. Erlandsen, "Effect of Hypoxia on Enterocyte Endocytosis of Enteric Bacteria," Critical Care Medicine, Vol. 24, No. 6, 1996, pp. 985-991. http://dx.doi.org/10.1097/00003246-199606000-00019

[46] N. A. Hering, M. Fromm and J. D. Schulzke, "Determinants of Colonic Barrier Function in Inflammatory Bowel Disease and Potential Therapeutics," The Journal of Physiology, Vol. 590, No. 5, 2012, pp. 1035-1044. http://dx.doi.org/10.1113/jphysiol.2011.224568

[47] M. Schumann, S. Kamel, M. L. Pahlitzsch, L. Lebenheim, C. May, M. Krauss, M. Hummel, S. Daum, M. Fromm and J. D. Schulzke, "Defective Tight Junctions in Refractory Celiac Disease," Annals of the New York Academy of Sciences, Vol. 1258, 2012, pp. 43-51. http://dx.doi.org/10.1111/j.1749-6632.2012.06565.x

[48] S. Zeissig, N. Bürgel, D. Günzel, J. Richter, J. Mankertz, U. Wahnschaffe, A. J. Kroesen, M. Zeitz, M. Fromm and J. D. Schulzke, "Changes in Expression and Distribution of Claudin 2, 5 and 8 Lead to Discontinuous Tight Junctions and Barrier Dysfunction in Active Crohn's Dis- 
ease," Gut, Vol. 56, No. 1, 2007, pp. 61-72. http://dx.doi.org/10.1136/gut.2006.094375

[49] Y. Ohashi, M. Hiraguchi, C. Sunaba, C. Tanaka, T. Fujisawa and K. Ushida, "Colonization of Segmented Filamentous Bacteria and Its Interaction with the Luminal IgA Level in Conventional Mice," Anaerobe, Vol. 16, No. 5, 2010, pp. 543-546. http://dx.doi.org/10.1016/j.anaerobe.2010.07.006

[50] L. A. van der Waaij, P. C. Limburg, G. Mesander and D. van der Waaij, "In Vivo IgA Coating of Anaerobic Bacteria in Human Faeces," Gut, Vol. 38, No. 3, 1996, pp. 348354. http://dx.doi.org/10.1136/gut.38.3.348

[51] D. A. Peterson, N. P. McNulty, J. L. Guruge and J. I. Gordon, "IgA Response to Symbiotic Bacteria as a Mediator of Gut Homeostasis," Cell Host \& Microbe, Vol. 2, No. 5, 2007, pp. 328-339. http://dx.doi.org/10.1016/j.chom.2007.09.013

[52] N. Shulzhenko, A. Morgun and W. Hsiao, et al., "Crosstalk between B Lymphocytes, Microbiota and the Intestinal Epithelium Governs Immunity versus Metabolism in the Gut," Nature Medicine, Vol. 17, No. 12, 2011, pp. 1585-1593.

[53] F. Pinheiro da Silva and M. C. Machado, "Antimicrobial Peptides: Clinical Relevance and Therapeutic Implications," Peptides, Vol. 36, No. 2, 2012, pp. 308-314. http://dx.doi.org/10.1016/j.peptides.2012.05.014

[54] C. L. Wilson, A. J. Ouellette, D. P. Satchell, T. Ayabe, Y. S. López-Boado, J. L. Stratman, S. J. Hultgren, L. M. Matrisian and W. C. Parks, "Regulation of Intestinal Alpha-Defensin Activation by the Metalloproteinase Matrilysin in Innate Host Defense," Science, Vol. 286, No. 5437, 1999, pp. 113-117. http://dx.doi.org/10.1126/science.286.5437.113

[55] N. H. Salzman, K. Hung, D. Haribhai, et al., "Enteric Defensins are Essential Regulators of Intestinal Microbial Ecology," Nature Immunology, Vol. 11, No. 1, 2010, pp. 76-83.

[56] Q. Li, C. Wang, C. Tang, N. Li and J. Li, "Molecular-phylogenetic Characterization of the Microbiota in Ulcerated and Non-ulcerated Regions in the Patients with Crohn's Disease," PLoS ONE, Vol. 7, No. 4, 2012, Article ID: e34939. http://dx.doi.org/10.1371/journal.pone.0034939

[57] X. Y. Qiu, M. M. Zhang, X. T. Yang, N. Hong and C. G. $\mathrm{Yu}$, "Faecalibacterium prausnitzii Upregulates Regulatory $\mathrm{T}$ cells and Anti-inflammatory Cytokines in Treating TNBS-induced Colitis," Journal of Crohn's \& Colitis, 2013, in press. http://dx.doi.org/10.1016/j.crohns.2013.04.002

[58] H. Sokol, B. Pigneur, L. Watterlot, O. Lakhdari, L. G. Bermúdez-Humarán, J. J. Gratadoux, S. Blugeon, C. Bridonneau, J. P. Furet, G. Corthier, C. Grangette, N. Vasquez, P. Pochart, G. Trugnan, G. Thomas, H. M. Blottière, J. Doré, P. Marteau, P. Seksik and P. Langella, "Faecalibacterium prausnitzii Is an Anti-Inflammatory Commensal Bacterium Identified by Gut Microbiota Analysis of Crohn Disease Patients," Proceedings of the National Academy of Sciences of the United States of America, Vol. 105, No. 43, 2008, pp. 16731-16736.

\section{http://dx.doi.org/10.1073/pnas.0804812105}

[59] V. Strugala, P. W. Dettmar and J. P. Pearson, “Thickness and Continuity of the Adherent Colonic Mucus Barrier in Active and Quiescent Ulcerative Colitis and Crohn's Disease," International Journal of Clinical Practice, Vol. 62, No. 5, 2008, pp. 762-769.

http://dx.doi.org/10.1111/j.1742-1241.2007.01665.x

[60] E. Amit-Romach, R. Reifen and Z. Uni, "Mucosal Function in Rat Jejunum and Ileum Is Altered by Induction of Colitis," International Journal of Molecular Medicine, Vol. 18, No. 4, 2006, pp. 721-727.

[61] C. Moehle, N. Ackermann, T. Langmann, C. Aslanidis, A. Kel, O. Kel-Margoulis, A. Schmitz-Madry, A. Zahn, W. Stremmel and G. Schmitz, "Aberrant Intestinal Expression and Allelic Variants of Mucin Genes Associated with Inflammatory Bowel Disease," Journal of Molecular Medicine, Vol. 84, No. 12, 2006, pp. 1055-1066. http://dx.doi.org/10.1007/s00109-006-0100-2

[62] M. Van der Sluis, B. A. De Koning, A. C. De Bruijn, et al., "Muc2-Deficient Mice Spontaneously Develop Colitis, Indicating that MUC2 Is Critical for Colonic Protection," Gastroenterology, Vol. 131, No. 1, 2006, pp. 117129. http://dx.doi.org/10.1053/j.gastro.2006.04.020

[63] L. Szentkuti, H. Riedesel, M. L. Enss, K. Gaertner and W. Von Engelhardt, "Pre-Epithelial Mucus Layer in the Colon of Conventional and Germ-Free Rats," The Histochemical Journal, Vol. 22, No. 9, 1990, pp. 491-497. http://dx.doi.org/10.1007/BF01007234

[64] C. Caballero-Franco, K. Keller, C. De Simone and K. Chadee, "The VSL\#3 Probiotic Formula Induces Mucin Gene Expression and Secretion in Colonic Epithelial Cells," American Journal of Physiology. Gastrointestinal and Liver Physiology, Vol. 292, No. 1, 2007, pp. 315-322. http://dx.doi.org/10.1152/ajpgi.00265.2006

[65] M. T. Abreu, "Toll-Like Receptor Signaling in the Intestinal Epithelium: How Bacterial Recognition Shapes Intestinal Function," Nature Reviews. Immunology, Vol. 10, No. 2, 2010, pp. 131-144.

[66] L. Frolova, P. Drastich, P. Rossmann, K. Klimesova and H. Tlaskalova-Hogenova, "Expression of Toll-Like Recaptor 2 (TLR2), TLR4, and CD14 in Biopsy Samples of Patients with Inflammatory Bowel Diseases: Upregulated Expression of TLR2 in Terminal Ileum of Patients with Ulcerative Colitis," The Journal of Histochemistry and Cytochemistry, Vol. 56, No. 3, 2008, pp. 267-274. http://dx.doi.org/10.1369/jhc.7A7303.2007

[67] N. Kamada, T. Hisamatsu, S. Okamoto, H. Chinen, T. Kobayashi, T. Sato, A. Sakuraba, M. T. Kitazume, A. Sugita, K. Koganei, K. S. Akagawa and T. Hibi, "Unique CD14 Intestinal Macrophages Contribute to the Pathogenesis of Crohn Disease via IL-23/IFN-gamma Axis," The Journal of Clinical Investigation, Vol. 118, No. 6, 2008, pp. 2269-2280. http://dx.doi.org/10.1172/JCI34610

[68] S. Rakoff-Nahoum, J. Paglino, F. Eslami-Varzaneh, S. Edberg and R. Medzhitov, "Recognition of Commensal Microflora by Toll-Like Receptors Is Required for Intestinal Homeostasis," Cell, Vol. 118, No. 2, 2008, pp. 229241. http://dx.doi.org/10.1016/j.cell.2004.07.002

[69] K. L. Edelblum, M. K. Washington, T. Koyama, S. 
Robine, M. Baccarini and D. B. Polk, "Raf Protects against Colitis by Promoting Mouse Colon Epithelial Cell Survival through NF-KappaB," Gastroenterology, Vol. 135, No. 2, 2008, pp. 539-551. http://dx.doi.org/10.1053/j.gastro.2008.04.025

[70] J. P. Hugot, M. Chamaillard, H. Zouali, et al., “Association of NOD2 Leucine-Rich Repeat Variants with Susceptibility to Crohn's Disease," Nature, Vol. 411, No. 6837, 2001, pp. 599-603. http://dx.doi.org/10.1038/35079107

[71] A. Rehman, C. Sina, O. Gavrilova, R. Häsler, S. Ott, J. F. Baines, S. Schreiber and P. Rosenstiel, "Nod2 Is Essential for Temporal Development of Intestinal Microbial Communities," Gut, Vol. 60, No. 10, 2011, pp. 1354-1362. http://dx.doi.org/10.1136/gut.2010.216259

[72] J. Wehkamp, N. H. Salzman, E. Porter, S. Nuding, M. Weichenthal, R. E. Petras, B. Shen, E. Schaeffeler, M. Schwab, R. Linzmeier, R. W. Feathers, H. Chu, H. Lima Jr., K. Fellermann, T. Ganz, E. F. Stange and C. L. Bevins, "Reduced Paneth Cell Alpha-Defensins in Ileal Crohn's Disease," Proceedings of the National Academy of Sciences of the United States of America, Vol. 102, No. 50, 2005, pp. 18129-18134.

http://dx.doi.org/10.1073/pnas.0505256102

[73] T. Watanabe, A. Kitani, P. J. Murray, Y. Wakatsuki, I. J. Fuss and W. Strober, "Nucleotide Binding Oligomerization Domain 2 Deficiency Leads to Dysregulated TLR2 Signaling and Induction of Antigen-Specific Colitis," Immunity, Vol. 25, No. 3, 2006, pp. 473-485. http://dx.doi.org/10.1016/j.immuni.2006.06.018

[74] T. Watanabe, N. Asano, P. J. Murray, K. Ozato, P. Tailor, Ivan J. Fuss, A. Kitani1 and W. Strober, "Muramyl Dipeptide Activation of Nucleotide-Binding Oligomerization domain 2 Protects Mice from Experimental Colitis," The journal of Clinical Investigation, Vol. 118, No. 2, 2008, pp. 545-549. http://dx.doi.org/10.1172/JCI33145

[75] S. Sepehri, R. Kotlowski, C. N. Bernstein and D. O. Krause, "Microbial Diversity of Inflamed and Noninflamed Gut Biopsy Tissues in Inflammatory Bowel Disease," Inflammatory Bowel Diseases, Vol. 13, No. 6, 2007, pp. 675-683. http://dx.doi.org/10.1002/ibd.20101 